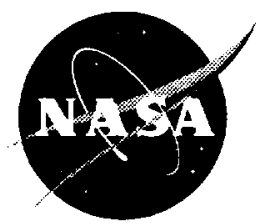

\title{
Collective Interaction in a Linear Array of Supersonic Rectangular Jets: a Linear Spatial Instability Study
}

Jeffrey Hilton Miles

Lewis Research Center, Cleveland, Ohio

Prepared for the

37th Aerospace Sciences Meeting \& Exhibit

sponsored by the American Institute of Aeronautics and Astronautics

Reno, Nevada, January 11-14, 1999

National Aeronautics and

Space Administration

Lewis Research Center 
Available from

NASA Center for Aerospace Information 800 Elkridge Landing Road Linthicum Heights, MD 21090-2934

Price Code: A03
National Technical Information Service 5285 Port Royal Road Springfield, VA 22100 Price Code: A03 


\title{
Collective interaction in a linear array of supersonic rectangular jets: a linear spatial instability study
}

\author{
Jeffrey Hilton Miles ${ }^{1}$ \\ National Acronautics and Space Administration \\ Lewis Rescarch Conter \\ Cleveland. OH 44135
}

\begin{abstract}
A lincar spatial instability model for multiple spatially periodic supersonic rectangular jots is solved using Floquet-Bloch theory. It is assumed that in the region of interest a coherent wave can propagate. For the case studied large spatial growth rates are found. This work is motivated by an increase in mixing found in experimental measurements of spatially periodic supersonic rectangular jots with phase-locked sereech and edge tone foedlback locked subsonic jets. The results obtained in this paper suggests that phase-locked sereceh or edge tones may produce correlated spatially periodic jet flow downstream of the nozzles which creates a large span wise multi-nozzlo region where a coherent wave cain propagate. The large spacial growth rates for eddies oldained by model calculation herein are related to the increased mixing since coddies are the primary mechanism that transfer cnergy from the mean flow to the large turbulent structures. Calculations of spacial growth rates will be presented for a set of relative Mach numbers and spracings for which $\mathrm{ex}$ perimental measurements have becen made. Calculations of spacial growth rates are presented for relative Mach numbers from 1.25 to 1.75 with ratios of nozzle spacing to nozzlc width ratios from $s / w_{N}=1$ to $\mathrm{s} / w_{N}=13.7$. The model may be of significant scientific and engincering value in the que'st to understand and construct supersonic mixer-cjector nozzles which provide increased mixing and reduced noise.
\end{abstract}

\section{Introduction}

Interest in proving the cconomic and cnvironmental feasibility of a high-speced civil transport has stimulated

\footnotetext{
${ }^{\perp}$ Acrospace Engineer, Member AIAA

Copyright (C) 1998 by the American lnstitute of Acronatics and Astronatutes, Inc. No copyright is asserted in the United State under Title 17, U.S. Code. The U.S. Government has at royalty-free license to exercise all rights under the copyright claimed lierein for Governmental I'urposes. All other rights are reserved by the copyright owner.
}

studies of mixing enhancement in lobed mixer-ejector nozzles. By cuhancing mixing the cjector length can be reduced with the same amount of noise suppression. In order to obtain information on such flows simpler configurations are studied. In particular. a simple mixer nozzle configuration consisting of multiple rectangular nozzles with a synchronized sereceh instability was studied by Taghavi and Raman' and Raman and Taghavi ${ }^{2.3}$. This nozzle showed increased mixing with the jets sunchror nized. This paper uses the geometry and flow conditions investigatcel by Raman and Taghavi ${ }^{3}$. The same bohavior is shown in a stuly of the effect of edge tones on multiple jot mixing of high-specd sulsonic flows by Krothapalli ('t . al. ${ }^{1}$ using the nozzk ekescribed by Krothapalli ct. al ${ }^{5}$.

It is propened that at some point before the jets merge local coherener wan loc achicved due to external forcing by screceth or aroustic fredback and large-scalc propagattion of instalsilitien arcurs with vary high growth rates. The temporal dymanies produced by the collective interaction of compurensilfe jets is discussed by Miles ${ }^{6}$ and the collective interatem of incompressible jets is discussed by Miles ${ }^{i}$. Howeres. the predictions of spatial instability theory have sluwn better agreement with experiment in free sheal flows and jots. Consequently this paper presents a spat ial ins ability analysis. Following Gaster. it is assumed the spattal instability analysis applies in a region where nonlineas effects are small. However. it is acknowledpord that the spatially growing linear theory will fail sine the anplitude of the disturbance must be bounderd.

For single nomgles a reduction in mixing and growth rates with increasing Mach number has been demonstrated experincutally by many investigators ${ }^{9-13}$. Corresponding lincar stability analysis of single nozzks shows results that are similar to the experimental studies ${ }^{1-16}$. This is attributed to the fact that eddies are the primary mechanism that transfer encrgy from the mean flow to the large turbulent structures. However. the following study is based on the idea that these experimental and theoretical results do not apply to the mixing of multiple supersonie rectangular jets with phasese lockerl sereceh. This paper is based on a linear stability analysis of compressible periodic parallel jot flows which was undertaken to obtain results related to lobed mixer nozzles. In this study, the lobed nozzle design concept is extrapolated in a one dimensional manner to arrive at an array of parallel rectangular nozzles separated by a distances where the smaller dimension of cach nozzle is $w_{N}$ 
and the longer dimension $b$ is taken to be infinite. Note that it is assumed that even widely spaced rectangular jets which are phase-locked by sercech are coherent spatially at sone distanec from the nozzle. Conscquently, in this lincar stalility analysis it is the collective behavior of compressible periodic parallel jot flow that determines the nozzle interaction.

In this paper. the behavior of the solutions is discussed and the trace of solutions is presented for a range of amplification curves. For cach operating condition, only the most highly amplified mode is of interest and special attention is paid to finding a good solution having the maximum amplification. Calculations of spatial growth rates are presented for relative Mach numbers from 1.25 to 1.75 with ratios of nozzle spacing to nozzle width ratios from $s / w_{N}=4$ to $s / w_{N}=13.7$. The actual values are those for which experimcntal data is presented by Raman and Taghavi $^{3}$.

\section{Results}

The nozzle configuration is shown in Fig. 1. In this paper, the flow is compressible and the velocity profile is adapted from an cquation used by Monkewit $z^{17}$ in a study of the absolute and convective instalsility of twodimensional wakes. A discussion of the problem formulation is given in Appendix A. Velocity profiles for ratios of nozzle spacing to nozzlo width of $s / w_{N}=5.5$ and $s / w_{N}=7.5$ are shown in Figure 2.

The linear spatial stability analysis is done using Floquet-Bloch theory. It is assumed that in the region of interest a coherent wave can propagate. This type of analysis for temporal stability has been applicd by Beaumont ${ }^{18}$ to an incompressible flow with a sinusoidal velocity profile perpendicular to the flow and by Miles ${ }^{6.7}$ to a compressible and incompressible periodic parallel jet flow. This analysis procedure is discussed in Appendix B.

Stability information is obtained using the flow model described in Appendix $A$ and the Floquet-Bloch method described in Appendix B. In this study of spatially growing waves proportional to $\exp \{\imath(\hat{k} \hat{x}-\hat{\omega} \tau)\}$ where $\hat{k}=$ $k L^{*}, \hat{x}=x / L^{*} . \hat{\omega}=\omega L^{*} / \Delta U$ and $\tau=t \Delta U / L^{*}$, the flow disturbance is characterized by a real frequency, $\hat{\omega}$. and a complex relative phase velocity, $\hat{c}=\hat{c}_{r}+i \hat{c}_{\imath}$ where $\hat{\omega} / \hat{k}=c / \Delta U=\bar{U} / \Delta U+\hat{r} / 2$. Conscquently, the phase velocity cigenfunction, $\hat{c}_{r}$, represents the phase velocity scaled by $\Delta U / 2$ and shifted by $\bar{U}$ where $\Delta U=U_{2}-U_{1}$ and $\hat{U}=\left(U_{1}+U_{2}\right) / 2$ so that for $\hat{c}_{r}=1$ the disturbance moves at velocity $U_{2}$, for $\hat{c}_{r}=-1$ the disturbance moves at velocity $U_{1}$ and for $\hat{c}_{r}=0$ the disturbance moves at velocity $\overline{\bar{U}}$. For a given value of jet relative Mach number, $m_{2}$, a value of the ratio of mean velocity to velocity difference, $U / \Delta U$, a ratio of inter jet spacing to rectangular nozzle smallest dimension. $\left(s / u_{N}\right)$. and $\hat{r}_{2}$, a range of $\hat{\omega}$ are studied to determinc if a growing disturbance with amplification,$-\hat{k}_{2}$, characterized by a periodicity parameter $\Gamma_{\imath}$ and a convective phase velocity $\hat{c}_{r}$ cxists. The computer program first evaluates solutions at one hundred fixed values of $\hat{c}_{r}$ in the range $-1<\hat{c}_{r}<1$. The wave number is given by $\hat{k}=\hat{\omega} /\left(\bar{U} / \Delta U+\hat{c}_{r} / 2+u \hat{c}_{l} / 2\right)$. Positive values of $\hat{c}_{2}$ are used in the range from 0 to 1 at intervals of 0.1 . since this produces negative $h$; values in a uscful range. A solution at a given value $\overrightarrow{r_{r}}$ is tabulated if the calculated value of $\Gamma_{1}$, is smaller than $5 . E-04$ and the calculated value of $|\delta|$ (defined in Appendix B) is less than 2. A further search is made in the $\hat{r}_{r}$ region where $\Gamma_{r}$ is smallest to find the best value of $c^{2}$. . An acceptable solution has $\Gamma_{r}$ smaller than $1 . E-06$ and the calculated valuc of $|\delta|$ less than 2 .

The reported results at cach value of $\hat{\omega}$ are limited to threc : no solution. one solution, or two solutions. It is possible that nore than two solutions exist. The model was developed to study amplification . $-\hat{k}_{i}$, over a range of Mach numbers and flow geometrics for compressible periodic parallel jet flow when the flow is correlated botween the jets.

The stability model is for shock-frec supersonic jets where no sereech tone exists. However. it does depend on the prescnce of a large span wise multi-nozzle region where a cohcrent wave can propagate. In this paper. it is suggested that this region can be created by phase locked screceh or edge-tones. Since sereech generally occurs within a frequency range where the instability waves arc highly amplified, the results from this study are used to explain certain events in screch synchronized multiple jets.

For cach condition studicd, solutions for a range of $\dot{\omega}$ values at a given value of $\hat{c}_{i}$ were produced to find the region where the maximum amplification. $-\hat{k}_{i}$, of the unstable wave occurred. The value of $\hat{c}_{i}$ used were between 0. and 1. using steps of 0.1. The value of $\hat{\omega}$ used was initialized at -0.005 and incremented by 0.005 . In general. blocks of $50 \hat{\omega}$ points were examined at a one time and the calculation for a particular valuc of $\hat{c}_{i}$ was abandoned if the current block of 50 points and the previous block of 50 points had no solutions.

To provide information on the spatial instability solution space, the trace of solutions for calculations of spatial amplification is prosented for $\vec{U} / \Delta U=0.5$. and a range of relative Mach numbers, $m_{2}=\Delta U / a_{2}$. and of and nozzle spacings $s / w_{n}$ shown in Tables 1 and 2 where the values selected are those for which experimental data is presented by Raman and Taghavi ${ }^{3}$.

Figures 3 thru 8 show plots of phase velocity cigenvaluc, $\hat{c}_{2}$, amplification, $\hat{k}_{2}$. periodicity factor, $\Gamma_{2}$ as a function of frequency, $\hat{\omega}$ for $0.1<c_{2}<1$ using steps of 0.1 for $c_{2}$. For a given value of $c_{2}$ the trace of points for the spatial stability solutions can be characterized as having two regions. At low frequencies the trace shows region or band where the unstable solutions are continuous. This region is generally followed at higher frequencies by isolated islands of instability. 
Parancter values for good solutions at the maximum growth rate for cach casc are prescinted in Tables 1 and 2. Values are sclected so that $\Gamma_{r}$ is smatler than $1 . E-(06$. Some points in Figure 7b) and 8b) have larger values of $-k_{i}$. However. for these points the value of $\Gamma_{r}$, was larger than $1 . E-06$ and they were rejected. In order to find a good solution a progression of points was cxamined until an acceptable point with $\Gamma$, is smaller than $1 . E-(06$ was found.

The nozzle width. $u_{N}^{*}$, is $0.0069 \mathrm{~m}$. The frequency of the instability is given by

$$
f_{r}^{*}=\frac{\hat{\omega}_{r} m_{2} a_{0}}{\left(1+\frac{s}{u_{v}}\right) u_{N}^{*}}
$$

where $a_{0}$ is the anbient speed of sound (nominally 333 $\mathrm{m} / \mathrm{sec}$ ). Values are given in Tables 1 and 2. Also shown in Tables 1 and 2 is the excitation sereceh frequency. $f_{s}$. The predicted instability frequency is about half the excitation frequency.

\section{Discussion}

A summary of the results of a study of temporal growth rates by Miles ${ }^{6}$ is shown in Figure 9. Large growth rates were found for a range of spacings .s/ $\omega_{N}$. and relative Mach numbers. $m_{2}$. At larger spacings and higher Mach numbers the temporal growth rate is reduced.

Figure 10 shows spatial growth rates. This paper shows similar trends when the spatial growth rate is calculated.

\section{Concluding Remarks}

A lincar instability model for a large span wise multinozzle region far downstream where a coherent wave can propagate is presented. Multiple supersonic rectangular jots exhibiting phasc-locked screcech or excited by edge tones may create such a region. The model may cxplain an increase in mixing observed in multiple jots exhibiting phase locked serrech. This work was conducted with the expectation that multi-jets with synchronized sereceh could provide increased mixing and reduced noise.

It might be that phase locked serech or edge tones can provide a contining mechanism which produces spatial coherence just as neighboring jets provided a confining mechanism in the experiments of Villermatux and Hopfinger ${ }^{19}$ and Villermatux, Gagne, and Hopfinger ${ }^{20}$.

The model may be of significant scientific and congineering value in the quest to understand and construct supersonic mixcr-cjector nozzles.

\section{Appendix A: Formulation of the problem}

Let $(U(y), 0.0)$ be the velocity of a steady planeparallel flow, where the $x$-axis is in the direction of the flow and

$$
U(y)=\bar{U} \cdot \frac{\Delta U}{2} h(y)
$$

where $U_{1}$ is the velocity outsiste the jot. $U_{2}$ is the moan centerline jet velocity $\bar{Q}=\frac{1+1 \%}{2}$. the velocity scale is $\Delta U=U_{2}-U_{1}$, and $h(y)$ is the velocity profile function which varies from - 1 to 1 .

The flow field is perturbed by introducing wave disturbances in the velocity and pressure with amplitudes that are a function of $\hat{y}$. These disturbanees are assumed to be traveling waves that are expressed in dimensionless variables ats

$$
\begin{aligned}
& (\bar{u} \cdot \hat{p}, \bar{u} \cdot \hat{p}) \\
= & (\ddot{u}(\hat{y}), \vec{u}(\hat{y}), \ddot{u}(\hat{y}), \tilde{p}(\hat{y})) \exp [i(\hat{k} \cdot \hat{x}-\hat{u} \tau)] .
\end{aligned}
$$

where $\tilde{u}, \tilde{r}$, and $\tilde{t}$ are dimensionless velocities. $\tilde{p}$ is the pressure, $\tau$ is the time. $\hat{x}$ is the distance along the jot flow. and $\hat{y}$ is the distance normal to the jot along the row of nozzles. The dimensionless variable used herein $\operatorname{arc} \hat{x}=x / L^{*} . \hat{y}=y / L^{*}$. and $\tau=t \Delta U / L^{*}$

The following quant it ies are also non-dimensionalized by a length scale, $L^{*}$ and a velocity scalc. $\Delta U$.

$$
\begin{aligned}
\hat{k} & =k L^{*}, \\
\hat{\omega} & =\frac{\omega L^{*}}{\Delta U} . \\
\hat{\omega} & =\frac{\omega}{h \Delta U}=\frac{r}{\Delta U}=i
\end{aligned}
$$

and we definc $\hat{c}$ as follows

$$
\dot{r}=\frac{\dot{c}}{\Delta U}=\frac{\bar{U}}{\Delta U}+\frac{\hat{c}}{2} .
$$

By definition for spacial instability, the frequency, $\dot{\omega}$. is a real positive number. $\hat{k}$ is a complex number that represents the wavenumber in the $x$-direction. $-h$, is 1 he amplification rate of the disturbance in the $\mathrm{x}$ direction. $\hat{r}$ a complex number that represents the relative phase velocity. Since

$$
\hat{k}=\frac{\hat{\omega}}{\frac{\bar{r}}{\Delta t}+\frac{\dot{c}_{r}+2 \dot{c}_{i}}{2}}
$$

by kecping $c_{1}$ positive and varying $\vec{c}$, between +1 and -1 $\hat{k_{i}}$ is always negative and only spatially growing solutions will be found.

From the equations of motion if nonlincar and viscous terms are neglected one can obtain an cequation for the $y$-component of the perturbation velocity as follows: 


$$
\begin{aligned}
\breve{r}^{\prime \prime} & -\breve{r}^{\prime}\left(\frac{\hat{T}^{\prime}}{\hat{T}}+\frac{A^{\prime}}{A}\right) \\
& -\breve{r}\left[\frac{h^{\prime \prime}}{(h-\hat{\imath})}+A \imath \hat{k}-\left(\frac{\hat{T}^{\prime}}{\hat{T}}+\frac{A^{\prime}}{A}\right) \frac{h^{\prime}}{(h-\hat{c})}\right]=0
\end{aligned}
$$

where the prines denote differentiation with respect to $\dot{y}$.

$$
\begin{array}{r}
A=-\imath \hat{k}+m^{2} \imath \hat{k} \cdot \frac{(h-\hat{r})^{2}}{4} \\
A^{\prime}=2 m^{2} \imath \hat{k} \cdot \frac{(h-\hat{c}) h^{\prime}}{4} \\
m^{2}=\frac{m_{1}^{2}}{\hat{T}}
\end{array}
$$

and from Crocco's Equation ${ }^{21}$

$$
\begin{aligned}
\hat{T}(y)=\frac{T(y)}{T_{1}}= & \frac{T_{2}}{T_{1}}+\frac{(1+h(y))}{2}\left(1-\frac{T_{2}}{T_{1}}\right) \\
& -\frac{1}{2}\left(m_{1}\right)^{2}(z-1) \frac{(h(y)+1)(h(y)-1)}{4}
\end{aligned}
$$

where

$$
\begin{aligned}
& m_{2}=\frac{\Delta U}{a_{2}} \\
& m_{1}=\frac{\Delta U}{a_{1}}=\frac{\Delta U}{a_{2}} \frac{\sqrt{T_{2}}}{\sqrt{T_{1}}}=m_{2} \frac{\sqrt{T_{2}}}{\sqrt{T_{1}}} .
\end{aligned}
$$

where $a_{1}$ is the local velocity of sound outside the jet, $a_{2}$ is the local velocity of sound inside the jet. $T_{1}$ is the local temperature outside the jet. and $T_{2}$ is the local temperat ure inside the jet.

In this paper. the velocity profile function. $h(y)$. is periodic such that

$$
h(y+2 \pi)=h(y)
$$

The velocity profilc $h(y)$ is not any exact solution of the Navier-Stokes equation, but it can be considered as a simple model of some real periodic flow.

The velocity profile $h(y)$ diseussed herein is given by

$$
h(y)=1-2 f(y)
$$

where the function $f(y)$ is given by

$$
f(y)=\frac{1}{\left[1+\left(\sinh \left(\frac{\eta}{\sinh (1)}\right)\right)^{18}\right]} .
$$

$\eta=\Lambda\left(-1+\frac{y}{)}\right)$. and $y$ goes from 0.0 to $2 \pi$. The profilc function $f(y)$ is adapted from an cquation uscel by Monkewitz ${ }^{17}$ in a study of the absolute and convective instability of two-dimensional wakes. Only twodimensional disturbances will be considered. A schematic of the nozzle gcometry is shown in Figure 1. Velocity profile using $\Lambda=1.22414$ and $\Lambda=1.73897$ are shown in Figure 2.

\section{Appendix B: Floquet-Bloch theory}

Since the basic flow velocity profilc , $f(y)$, is periodic. equation (1) is an example of a Floquet-Bloch problem. The mathematics of solving Floquet-Bloch type problems is discussed by Ince ${ }^{22}$. Hochstadt ${ }^{23}$, and Zwillinger ${ }^{21}$. Applications to solid state physics are discussed by Sachs $^{25}$. Brillouin ${ }^{26}$. and Dekker ${ }^{27}$. Applications to spratially periodic flow are discussed l,y Lorenz $z^{28}$, Circen ${ }^{29}$, Bcaumont ${ }^{18}, \mathrm{Ba}^{30}$ and Gotoh ${ }^{31.32}$.

The paper by $\mathrm{B}$ atumont ${ }^{18}$ and the description of the Floquet-Blod theorem by Hochstadt ${ }^{23}$ were particularly uscful in guiding this rescarch.

A survey of the spatially periodic flow literature is presented by K. Gowoh and M.Y. Yamada ${ }^{33}$.

The second order differential equation can be described by a system of first order differential equations. Let

$$
\begin{aligned}
\check{r} & =x_{1} \\
\ddot{r}^{\prime} & =x_{2}
\end{aligned}
$$

so that Eq. 1 (an be rewritten as the system

$$
\begin{aligned}
& r_{1}^{\prime}=r_{2} \\
& x_{2}^{\prime}=L x_{1}+C x_{2}
\end{aligned}
$$

where

$$
C^{\prime}=\left(\frac{\hat{T}^{\prime}}{\hat{T}}+\frac{A^{\prime}}{A}\right)
$$

and

$$
D=\left[\frac{h^{\prime \prime}}{(h-\hat{\imath})} \cdot A i \hat{k}-\left(\frac{\hat{T}^{\prime}}{\hat{T}}+\frac{A^{\prime}}{A}\right) \frac{h^{\prime}}{(h-\hat{\hat{C}})}\right]
$$

If $\boldsymbol{\Phi}(y)$ is a fundinnental matrix solution of cquation ( (2) ) such thit

$$
\Phi(0)=\mathbf{I}
$$

where $I$ is the idcentity matrix, then from the FloquetBloch theorem

$$
\Phi(y+2 \pi)=\Phi(y) \Phi(2 \pi)
$$

We now introduce two solutions of equation ( 2$)$ with initial values at $y=0.0$. Wo have $\Phi(0)=\left[\phi_{1}(0), \phi_{2}(0)\right]$ where $\phi(0)_{1}=1, \phi^{\prime}(0)_{1}=0, \phi(0)_{2}=0$, and $\phi(0)_{2}^{\prime}=1$. Next we scek the cigenvalues of $\Phi(2 \pi)$

$$
\begin{aligned}
& |\boldsymbol{\Phi}(2 \pi)-\mu \mathbf{I}| \\
= & \mu^{2}-\left(\phi_{1}(2 \pi)+\phi_{2}{ }^{\prime}(2 \pi)\right) \mu \\
& +\left(\phi_{1}(2 \pi) \phi_{2}{ }^{\prime}(2 \pi)-\right. \\
& \left.\phi_{2}(2 \pi) \phi_{1}{ }^{\prime}(2 \pi)\right) \\
= & \mu^{2}-\left(\phi_{1}(2 \pi)+\phi_{2}{ }^{\prime}(2 \pi)\right) \mu+1=0
\end{aligned}
$$


Since

$$
\phi_{1}(2 \pi) \phi_{2}{ }^{\prime}(2 \pi)-\phi_{2}(2 \pi) \phi_{1}{ }^{\prime}(2 \pi)=|\Phi(2 \pi)|=|\Phi(0)|=1
$$

The independent solutions of equation (2) have the form

$$
\phi=X(y) \exp \left(\frac{\log (\mu)}{2 \pi} y\right)=X(y) \operatorname{cxp}(\Gamma y)
$$

The paraneter $\Gamma$ specifies the period of the cigenfunction $\phi$. If $I$ is real the cigenfunction grows or decays at infinity. Consequently. only imaginary values of $\Gamma$ are acecptal)le. Thus the (igenfunction oscillates in space and is called a continuous mode. The disturbance with $\Gamma_{i}=1 / n$. where $n$ is a nonzero integer. has a period $2 n \pi$. One with $\Gamma_{i}=0$ hats the same period $2 \pi$ as the main flow: whilc an irrational value of $L_{;}$means the disturbance is apcriodic. Note that the paraneter I does not appear in the flow equation. but is due to the Floquet-Bloch theorem.

Solutions of 2 are thus of the form

$$
\begin{aligned}
& X_{1}(y+2 \pi)=\mu_{1} X_{1}(y) \\
& X_{2}(y+2 \pi)=\mu_{2} X_{2}(y)
\end{aligned}
$$

where $\mu_{1}$ and $\mu_{2}$ represent the zeros of (3). provided they arc distinct.

In general, these solutions will not be periodic.

Conditions for periodic solutions can be found as follows

Lot $\mu_{1}=\epsilon^{i H_{i}}$ and $\mu_{2}=\mathrm{f}^{-i H_{i}}$.

Then from cquation (3)

$$
\cos \left(\theta_{i}\right)=\phi_{1}(2 \pi)+\phi_{2}{ }^{\prime}(2 \pi)=\delta / 2
$$

Conscquently. for a solution to be periodic $\delta$ must be real and $|\delta|$ smaller tham 2.

The constants $\mu$ are termed the characteristic multiplicrs of the Floguet-Bloch system (2) and the corresponding characteristic exponents are determined by the relattion $\Gamma=\Gamma_{r}+i \Gamma_{i}=\frac{\log (\mu)}{2 \pi}=\frac{\theta_{r}}{2 \pi}+i \frac{\Theta_{i}}{2 \pi}$.

\section{References}

${ }^{1}$ R. Taghavi and G. Raman. Enhanced mixing of multiple supersonic rectangular jets by synchronized screech. $A I A A$ Journal, $32: 2477-2481$, 1991

${ }^{2}$ Ganesh Raman and Ray Taghavi. Resonant interaction of a lincar array of supersonic rectangulas jet: an experimental study. AIAA-95-0510 puper presented at the 33ro Aerospace Sciences Mecting atud Exhibit Jamuary 3 12, Remu, NV, 1995.

"Ganesh Raman and Ray Taghavi. Resonant interaction of a lincar array of supersonic rectangulary jets: an experemental study: J. Fluid Mech, $\mathbf{3 0 9}: 93$ 111, 1996

A. Krothapalli, K. Karancheti, Y. Hsia, and D. Baganoff. Edge tones in high-speed flows and their application to nultiple-jot mixing. AIAA Journal, 21 No. $\mathrm{\imath}: 937-938$, July 19831983
'A. Krothapalli, D. Baganolf, and K. Karamcheti. Derelopment and structure of a rectangular jet in a multiple jet configuration. AIAA Journal, 18 No. 8:945-950, August 19801980.

"Jufrey Hilton Miles. Collective Interuction of a Compressible Periodic Parallel Jet Flow. Tedinical Report, AIAA97-(1)50. NASA Technical Menorandum 107467, 1997.

7.Jffrey Hilton Miles. Wave number selection for incompressible parallel jet flows periodic in space. Technical Report, AIAA-97-1996, NASA Technical Memorandum $10 \mathrm{~T} 468,199 \mathrm{~T}$.

"M. Gaster. On the generation of spatially growing waves in a boundary layer. J. Fluid Mcch, 22 Paut 3:433-441, 1965.

"D. Papamoschou and A. Roshko. Obscrvations of supersonic free shcar layers. AIAA 86-0162. 1986.

${ }^{10}$ Dimitri Papamoschou. Experimental Innestigation of Hotcrogencous Compressible. Shear Layers. PhD thesis, California Institute of Teclinology, Pasadena, California, 1987.

${ }^{1}$ D. Papamoschou and A. Roshko. The compressible turbulent shear layer: an experinental study. J. Fluid Mech., 197 No.:453-477, 1988.

${ }^{2}$ N. Chinzei, G. Masuya, T. Komuro, A. Murakami, and D. Kudou. Spreading of two-streans supersonic turbulent mixing layers. The Physics of Fluids, 29 No.5:1345-1347, 1986.

1: M. Saminy and G. S. Elliot t. Effects of compressibility on the structure of free shear layers. $A I A A$ 88-3054, 1988.

${ }^{1}$ Hans Gropengiesser. On the stability of free shear layers in compressible flows. (in German) Bcitrog zur Stabilitat freier Grenzschichten in hompressiblen Medien: Deutsche: Luft. und Raumfahrt, Report DLR FB-69-25, 123 pp., 1969. Also NASA T T F-12,786 (1970) and NT1-32468.

1. S. A. Ragab and J. L. Wu. Instabilities in the free shear layer formed by two supersonic streams. AIAA Paper 88 00138,1988

"Mei Zhuang, T. Kubota, and P. E. Dimotakis. On the instability of inviscid, compressible frec shear layers. Conference. Proe. 1st National Fluid Dyn. Cong. July 25-28 Cincinnati, Ohio, $768 \cdot 773,1988$.

1: Peter A. Monkewitz. The absolute and convective nature of instability in two-dimensional wakes at low reynolds numbess. Phys. Fluids, 31No.5:999-1006, May 1988.

${ }^{2}$ D. N. Beatumont. The stability of spatially periodic Hows. J. Fluid Mech, 108 :461-474, 1981

${ }^{\circ}$ E. Villernaux and E.J. Hopfinger. Periodically arranged co-flowing jets. J. Fluid Mech., 263 No.:63 92, 1994.

21) E. Villermatux, Y. Gagne, and E.J. Hopfinger. Solf sustained oscillations and collective behavionss in a lattice of jets. Applied Scientific. Rescureh, 51 :243 248, 1993.

2: Hormann Schlichting. Boundary-Layer Theory. McGrawHill Book Company, 1968.

$22 \mathrm{E}$. L. Ince, Orvinary differential cquations. Dorer, 1926,1956. pp. 381-382.

2:3 Harry Hochstadt. Differential Equations. Dower, 1963. pp. 195200.

21 Danid Zwillinger. Handbook of Differential Equations. Academic I'ress, 1992. pu. 448-118.

2. Mendel Sachs. Solud State Theory. Dower, 1963. pp. 189 198. 
${ }^{26}$ L. Brillouin. Wave Propagation in Periodic Structures. Dover Publications, Inc., 1946. pp. 172-186.

${ }^{27}$ Adrianus J. Dekker. Solid State Physics. Prentice-Hall, Inc., 1962. pp.238-250.

${ }^{2 \times}$ Edward N. Lorenz. Barotropic instability of rossby wave motion. Journal of the Atmospheric Sciences, 29 :258-264, March 1972 .

29 J. S. A. Green. Two-dimensional turbulence near the viscous linit. J. Fluid Mcch, 62 :273-287, 1974.

${ }^{30}$ Dov Bai and Joseph B. Keller. Sound waves in a periodic medium containing rigid spheres. J. Acoust. Soc. Am, 82 (4):1436-1441, October 1987.
${ }^{31}$ Kancfusa Gotoh, Michio Yamada, and Jiro Mizushima. The theory of stability of spatially periodic parallel flows. J. Fluid Mech., 127:45-58, 1983.

32 Michio Yamada. Nonlincar stability thcory of spatially periodic parallel flows. Journal of the Physical Society of Jupun, 55No.9:3073-3079, Scptenber 1986.

${ }^{33} \mathrm{~K}$. Gotoll and M. Yamada. Stability of spatially periodic Hows. In unknown, editor, Encyclopedia of Fluid Mechanies, chapter 19, pages 589-610, Houston, Tex: Gulf, 1986. 
TABLE I.-PARAMETER VALUES AT MAXIMUM

GROWTH RATE FOR $\mathrm{m}_{2}=1.25, \mathrm{~m}_{2}=1.35$

AND $m_{2}=1.45$

\begin{tabular}{|l|l|l|l|}
\hline Parameter & \multicolumn{1}{|c|}{$\mathrm{m}_{2}=1.25$} & \multicolumn{1}{c|}{$\mathrm{m}_{2}=1.35$} & \multicolumn{1}{c|}{$\mathrm{m}_{2}=1.45$} \\
\hline $\mathrm{A}$ & 1.294735 & 1.22414 & 1.73897 \\
\hline$s / w_{N}$ & 4 & 5.5 & 7.5 \\
\hline$L^{*}$, meters & $5.491 \times 10^{-3}$ & $7.1380 \times 10^{-3}$ & $9.3344 \times 10^{-3}$ \\
\hline$f_{s}, \mathrm{~Hz}$ & 12192 & 10200 & 8512 \\
\hline$f_{r}^{*}, \mathrm{~Hz}$ & 6696 & 5412 & 4651 \\
\hline$f_{r}^{*} / f_{,}$ & 0.549 & 0.545 & 0.546 \\
\hline$\hat{\omega}_{r}$ & 0.555 & 0.54 & 0.565 \\
\hline$\hat{c}_{r}$ & -0.29605 & -0.29936 & -2.2653 \\
\hline$\hat{c}_{i}$ & 0.4 & 0.4 & 0.4 \\
\hline$\hat{k}_{r}$ & 1.192 & 1.1625 & 1.1527 \\
\hline$\hat{k}_{i}$ & -0.6773 & -0.6637 & -0.59611 \\
\hline$\delta_{r}$ & 0.50985 & -0.90483 & -1.8499 \\
\hline$\delta_{i}$ & $-1.5534 \times 10^{-10}$ & $2.1089 \times 10^{-6}$ & $1.4473 \times 10^{-7}$ \\
\hline$\Gamma_{i}$ & 0.2897 & 0.17528 & $6.2044 \times 10^{-2}$ \\
\hline$\Gamma_{r}$ & $-1.2784 \times 10^{-11}$ & $-1.8818 \times 10^{-1}$ & $-3.0307 \times 10^{-8}$ \\
\hline $\mid \delta$ & 0.50985 & 0.90483 & 1.8499 \\
\hline
\end{tabular}

TABLE II.-PARAMETER VALUES AT MAXIMUM GROWTH RATE FOR $\mathrm{m}_{2}=1.55, \mathrm{~m}_{2}=1.65$ AND $m_{2}=1.75$

\begin{tabular}{|l|l|l|l|}
\hline Parameter & \multicolumn{1}{|c|}{$\mathrm{m}_{2}=1.55$} & \multicolumn{1}{c|}{$\mathrm{m}_{2}=1.65$} & \multicolumn{1}{c|}{$\mathrm{m}_{2}=1.75$} \\
\hline $\mathrm{A}$ & 1.139382 & 1.1258595 & 1.111845 \\
\hline$s / \omega_{N}$ & 10 & 11.5 & 13.7 \\
\hline$L^{*}$, meters & $1.208 \times 10^{-2}$ & $1.3727 \times 10^{-2}$ & $1.6143 \times 10^{-2}$ \\
\hline$f_{s}, \mathrm{~Hz}$ & 7136 & 5952 & 5280 \\
\hline$f_{r}^{*} \cdot \mathrm{Hz}$ & 3876 & 3344 & 2183 \\
\hline$f_{r}^{*} / f_{s}$ & 0.543 & 0.562 & 0.413 \\
\hline$\hat{\omega}_{r}$ & 0.57 & 0.525 & 0.38 \\
\hline$\hat{c}_{r}$ & -0.105 & $4.3075 \times 10^{-2}$ & -0.81295 \\
\hline$\hat{c}_{i}$ & 0.4 & 0.4 & 1.0 \\
\hline$\hat{k}_{r}$ & 1.0617 & 0.87758 & 0.13735 \\
\hline$\hat{k}_{i}$ & -0.47449 & -0.33654 & -0.73431 \\
\hline$\delta_{r}$ & -1.8094 & -1.5363 & $4.9339 \times 10^{-2}$ \\
\hline$\delta_{i}$ & $8.7953 \times 10^{-8}$ & $8.3042 \times 10^{8}$ & $1.1 \times 10^{-1}$ \\
\hline$\Gamma_{i}$ & $7.0048 \times 10^{-2}$ & 0.11059 & 0.24607 \\
\hline$\Gamma_{r}$ & $-1.6428 \times 10^{-8}$ & $-1.0321 \times 10^{-8}$ & $8.756 \times 10^{-9}$ \\
\hline $\mid \delta$ & 1.8094 & 1.5363 & $4.9838 \times 10^{-2}$ \\
\hline
\end{tabular}




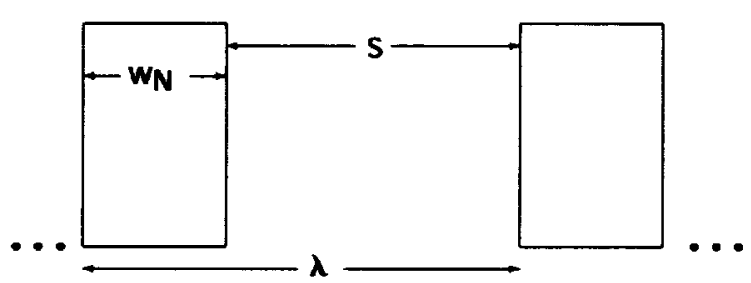

Figure 1.-Nozzle configuration.

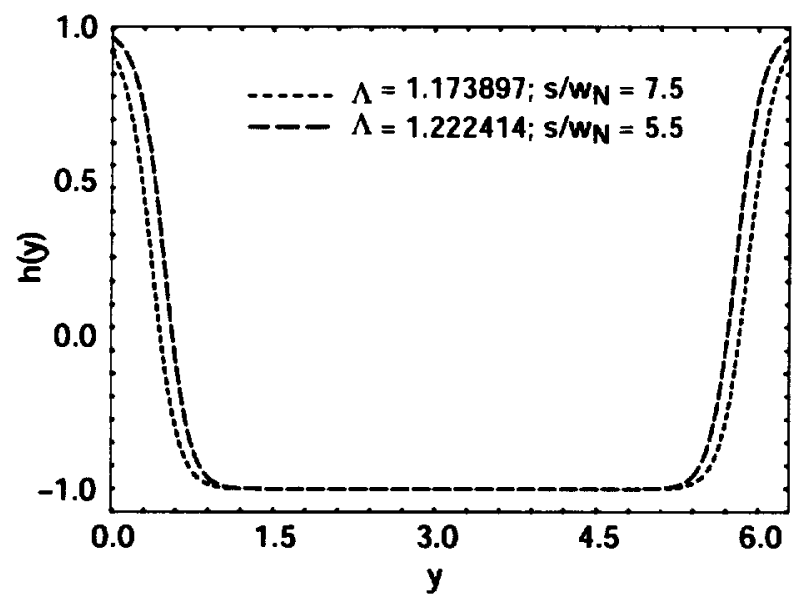

Figure 2.-Typical velocity profile. $(\Lambda=1.173897$; $s / w_{N}=7.5$ and $\Lambda=1.22414 ;\left(s / w_{N}=5.5\right)$. 


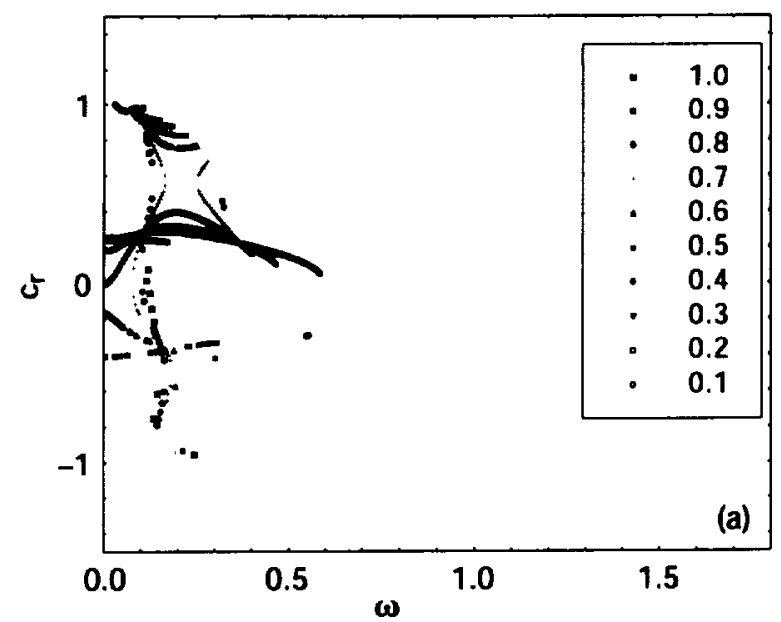

Figure 3.-(a) Phase velocity eigenvalue, $c_{r}$, verses frequency, $\dot{w}$, for 0.1 $<\dot{c}_{i}<1.0 .\left(s / w_{n}=4.0 ; \Lambda=1.294735 ; U ̈ / \Delta U=0.5 ; m_{2}=1.25 ; T_{2}=1\right)$.

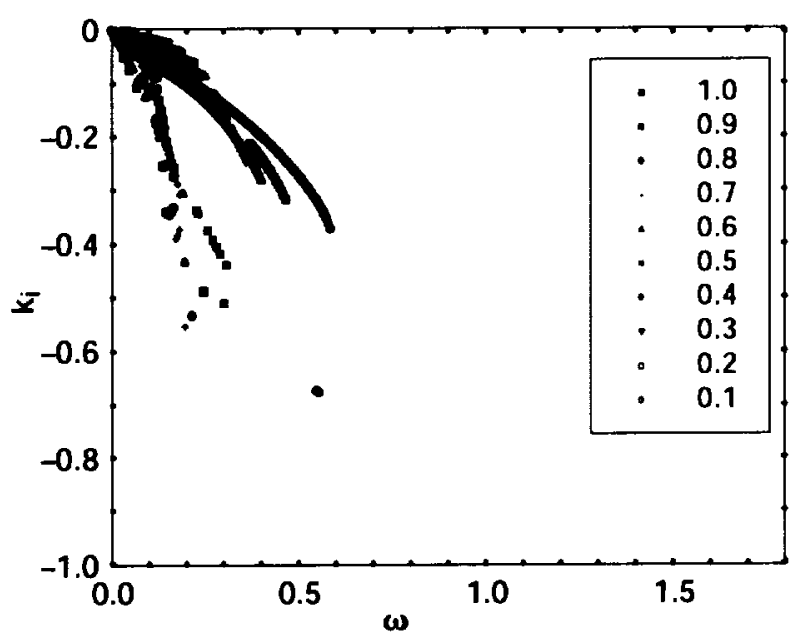

Figure 3.-(b) Amplification, $k_{i}$, verses frequency, $\hat{w}_{\text {, for }} 0.1<\hat{\mathbf{c}}_{\mathrm{i}}<\mathbf{1 . 0}$. $\left(s / w_{n}=4.0 ; \Lambda=1.294735 ; \tilde{U} / \Delta U=0.5 ; m_{2}=1.25 ; T_{2}=1\right)$.

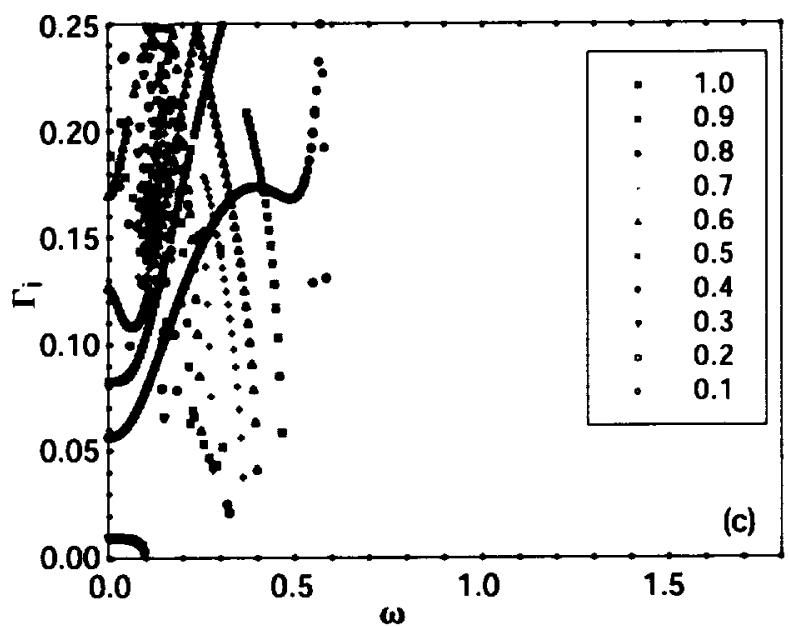

Figure 3.-(c) Periodicity factor, $\Gamma_{i}$, verses frequency, $\hat{w}$, for $0.1<\hat{c}_{i}<$ 1.0. $\left(s / w_{n}=4.0: \Lambda=1.4735 ; U / \Delta U=0.5 ; m_{2}=1.25 ; T_{2}=1\right)$. 


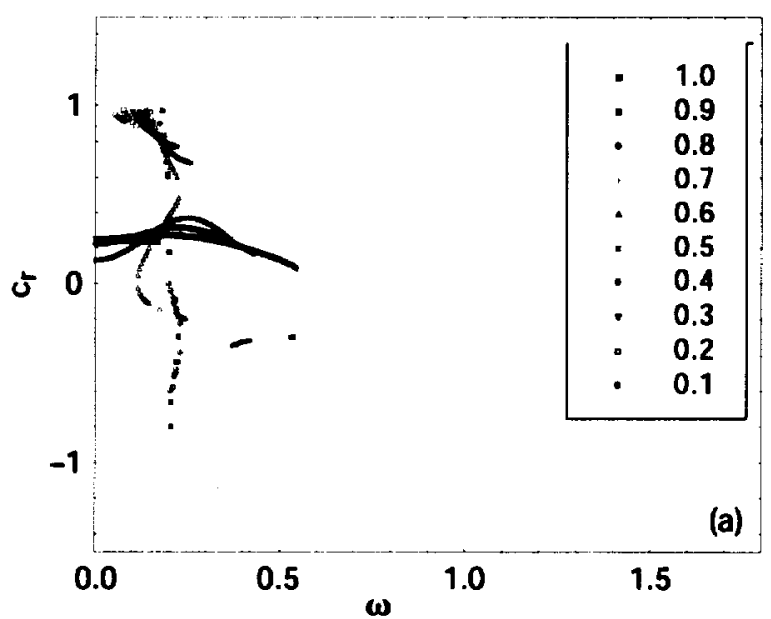

Figure 4.-(a) Phase velocity eigenvalue, $c_{r}$, verses frequency, $\hat{w}$, for 0.1 $<\dot{c}_{i}<0.9 .\left(s / w_{n}=5.5 ; \Lambda=1.22414 ; \dot{U} / \Delta U=0.5 ; m_{2}=1.35 ; T_{2}=1\right)$.

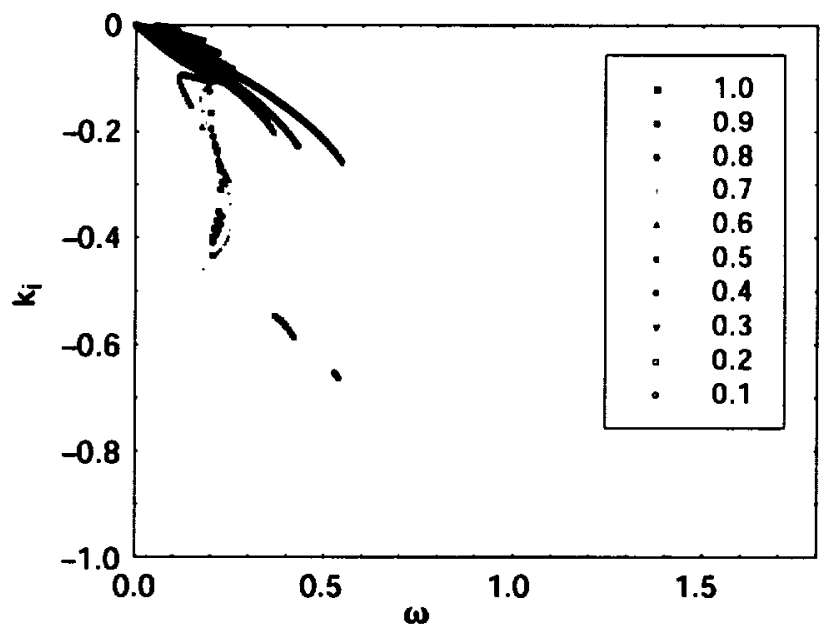

Figure 4.-(b) Amplification, $k_{j}$, verses frequency, $w$, for $0.1<\dot{c}_{j}<0.9$. $\left(s / w_{n}=5.5 ; \Lambda=1.22414 ; \bar{U} / \Delta U=0.5 ; m_{2}=1.35 ; T_{2}=1\right)$.

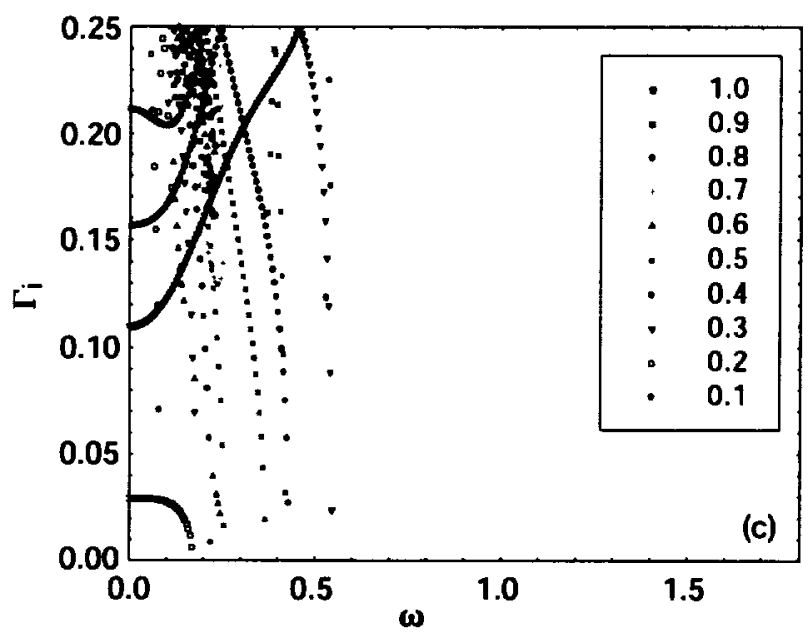

Figure 4.-(c) Periodicity factor, $\Gamma_{j}$, verses frequency, $\hat{w}$, for $0.1<\dot{c}_{i}<$ 0.9. $\left(\mathrm{s} / \mathrm{w}_{\mathrm{n}}=5.5 ; \Lambda=1.22414 ; \bar{U} / \Delta \mathrm{U}=0.5 ; \mathrm{m}_{2}=1.35 ; \mathrm{T}_{2}=1\right)$. 


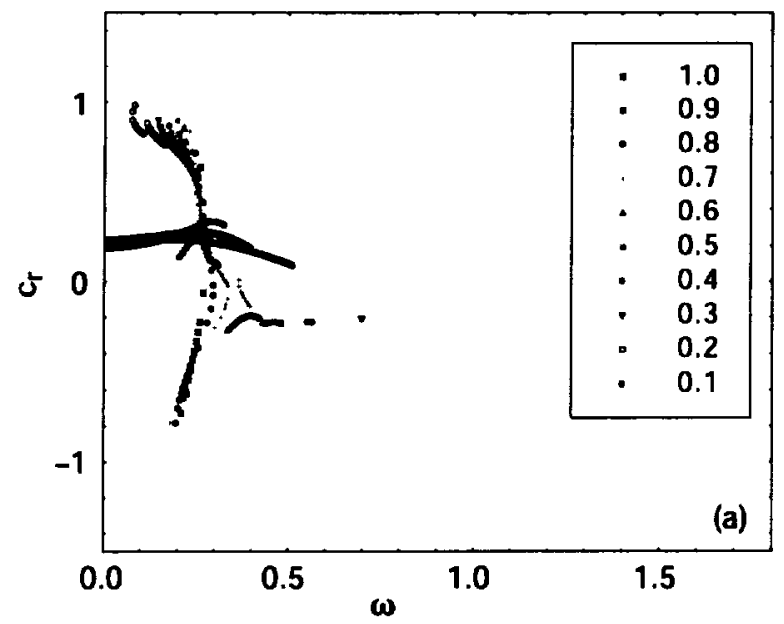

Figure 5.-(a) Phase velocity eigenvalue, $c_{r}$, verses frequency, $\hat{w}_{\text {, for } 0.1}$ $<\dot{c}_{i}<1.0 .\left(s / w_{n}=7.5 ; \Lambda=1.173897 ; U / \Delta U=0.5 ; m_{2}=1.45 ; T_{2}=1\right)$.

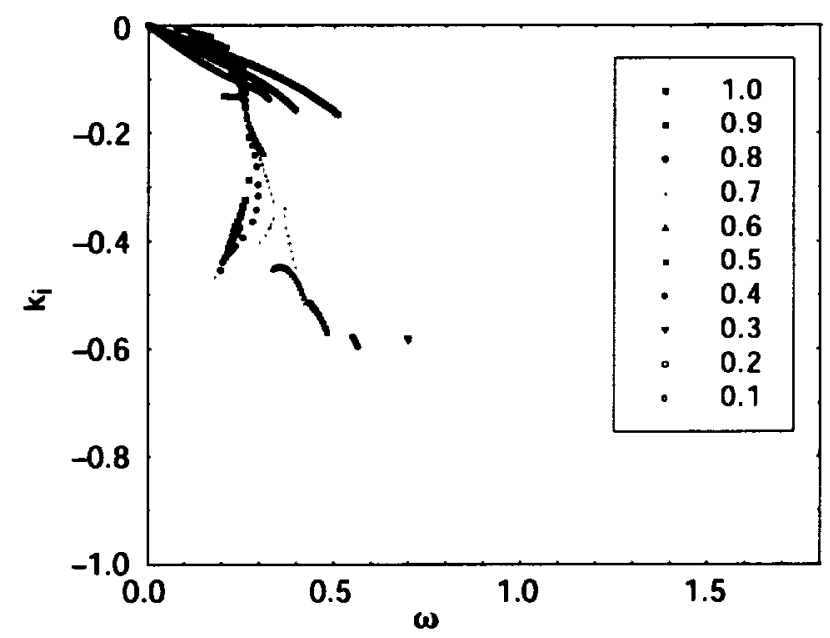

Figure 5.-(b) Amplification, $k_{i}$, verses frequency, $w_{\text {, for }} 0.1<\dot{c}_{i}<$ 1.0. $\left(s / w_{n}=7.5 ; \Lambda=1.173897 ; U ̈ / \Delta U=0.5 ; m_{2}=1.45 ; T_{2}=1\right)$.

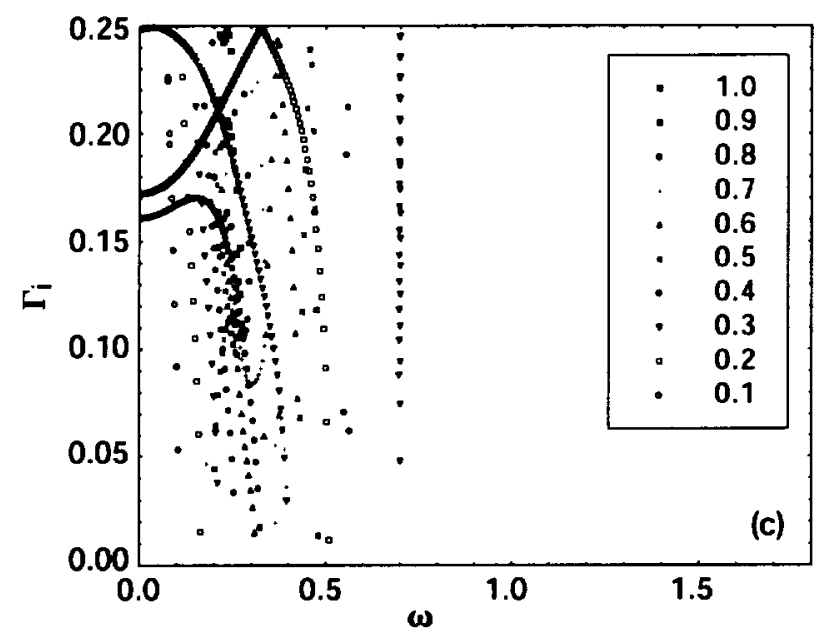

Figure 5.-(c) Periodicity factor, $\Gamma_{i}$, verses frequency, $\dot{w}$, for $0.1<\dot{c}_{i}<$ 1.0. $\left(s / w_{n}=7.5 ; \Lambda=1.173897 ; U / \Delta U=0.5 ; m_{2}=1.45 ; T_{2}=1\right)$. 


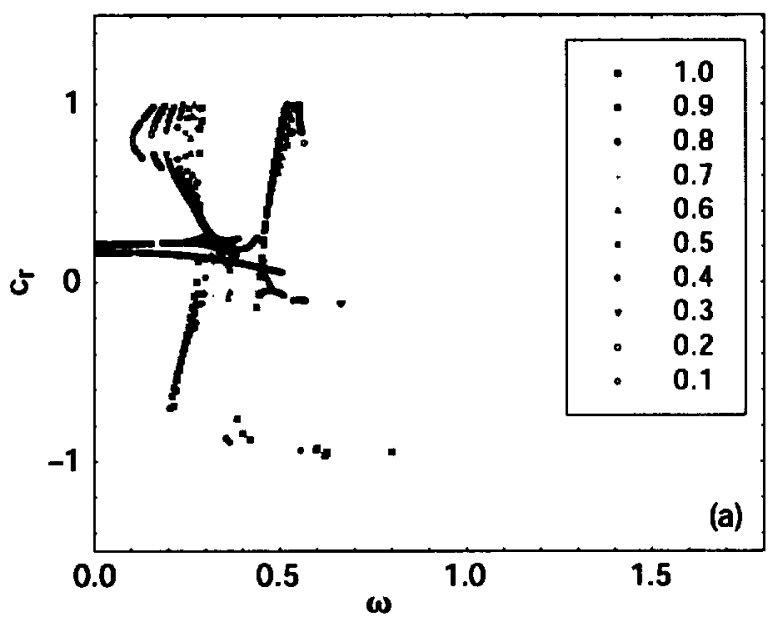

Figure 6.-(a) Phase velocity eigenvalue, $c_{r}$, verses frequency, $\hat{w}$, for 0.1 $<\dot{c}_{j}<1.0 .\left(s / w_{n}=10.0 ; \Lambda=1.139382 ; \dot{U} / \Delta U=0.5 ; m_{2}=1.55 ; T_{2}=1\right)$.

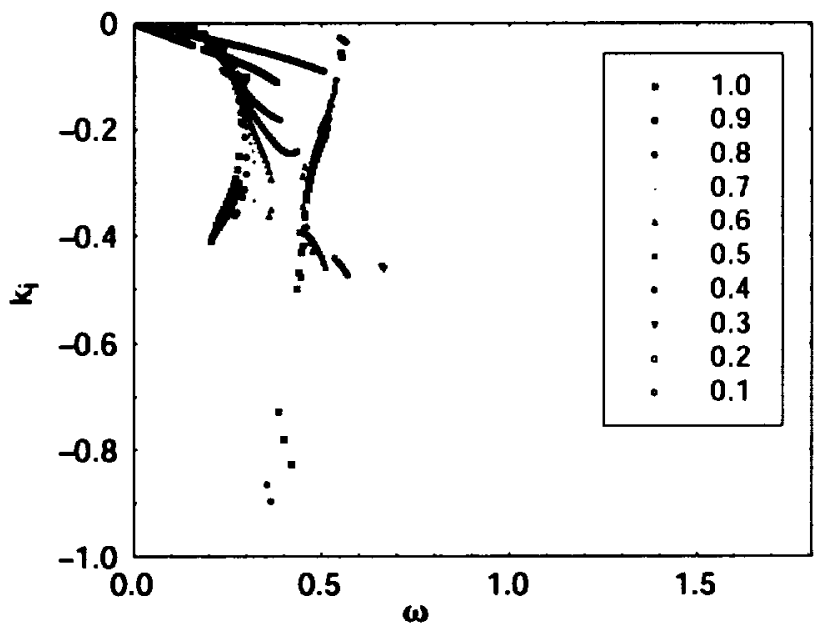

Figure 6.-(b) Amplification, $k_{j}$, verses frequency, $w$, for $0.1<\dot{c}_{j}<$ 1.0. $\left(s / w_{n}=10.0 ; \Lambda=1.139382 ; U / \Delta U=0.5 ; m_{2}=1.55 ; T_{2}=1\right)$.

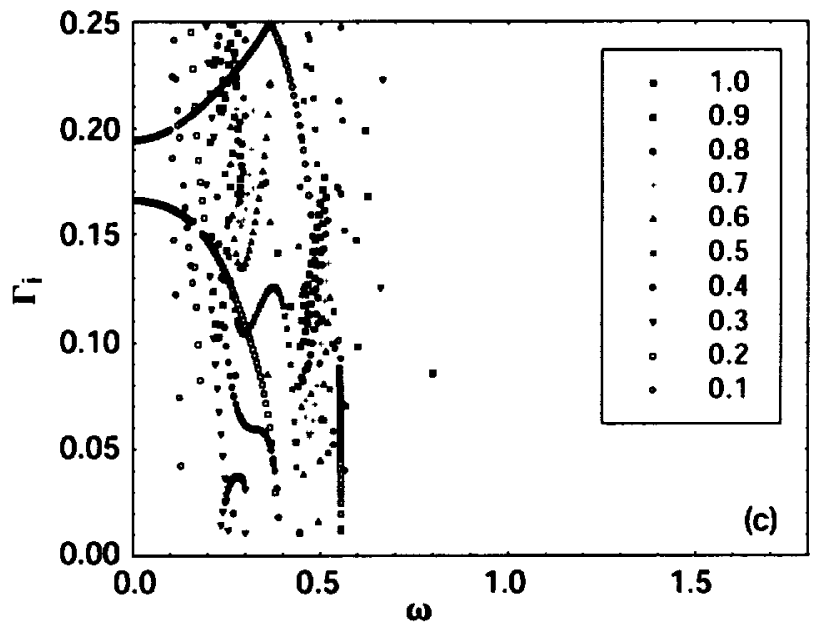

Figure 6.-(c) Periodicity factor, $\Gamma_{\hat{j}}$, verses frequency, $\dot{w}$, for $0.1<\dot{c}_{j}<$ 1.0. $\left(s / w_{n}=10.0 ; \Lambda=1.139382 ; U / \Delta U=0.5 ; m_{2}=1.55 ; T_{2}=1\right)$. 


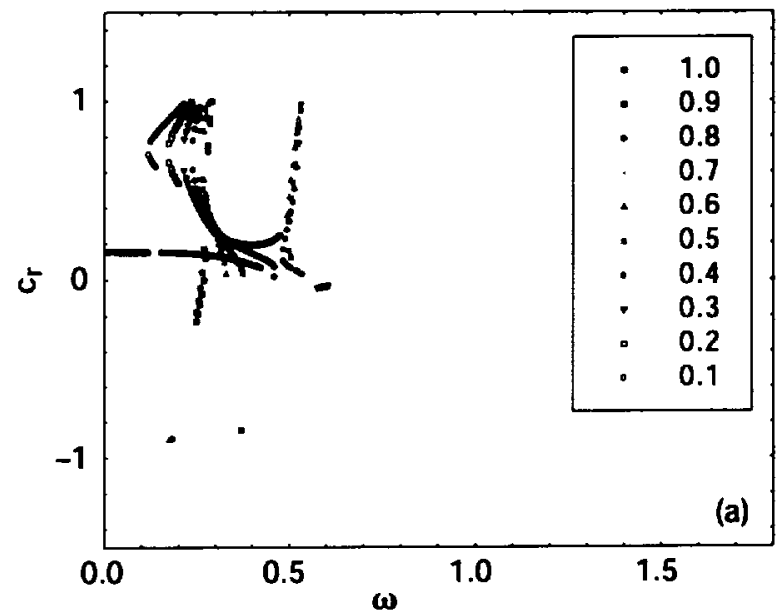

Figure 7.-(a) Phase velocity eigenvalue, $c_{r}$, verses frequency, $\dot{w}$, for 0.1 $<\dot{c}_{i}<1.0 .\left(s / w_{n}=11.5 ; \Lambda=1.1258595 ; \dot{U} / \Delta U=0.5 ; m_{2}=1.65 ; T_{2}=1\right)$.

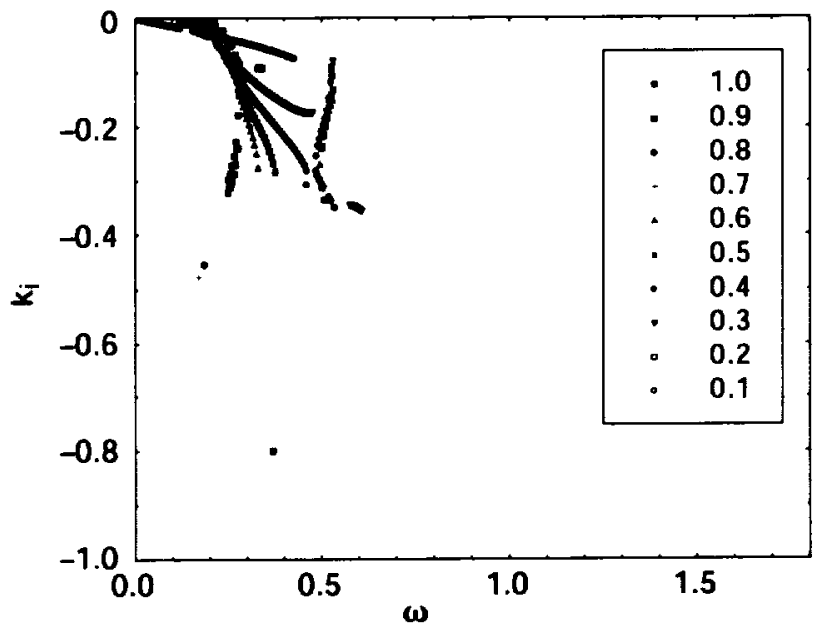

Figure 7.-(b) Amplification, $k_{i}$, verses frequency, $w$, for $0.1<\dot{c}_{i}<$ 1.0. $\left(s / w_{n}=11.5 ; \Lambda=1.1258595 ; U ̈ / \Delta U=0.5 ; m_{2}=1.65 ; T_{2}=1\right)$.

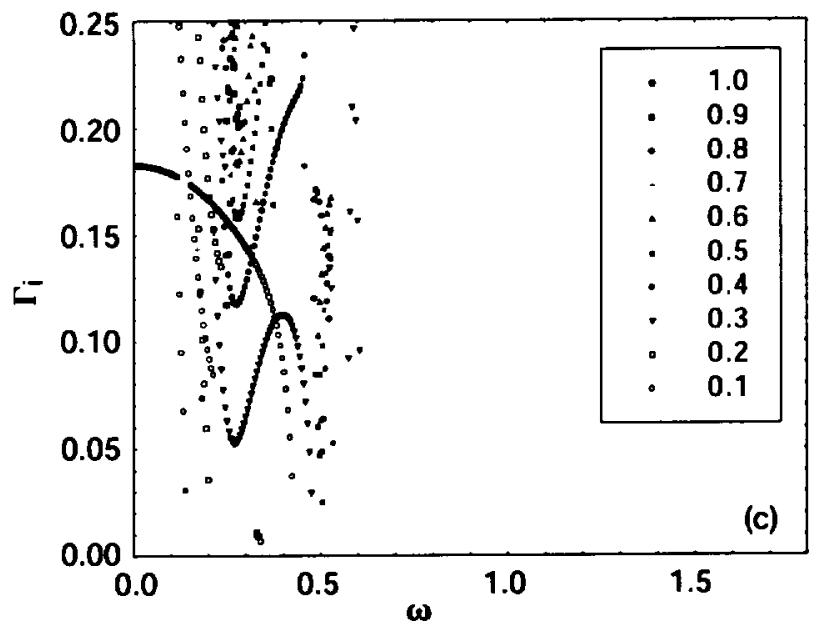

Figure 7.-(c) Periodicity factor, $\Gamma_{j}$, verses frequency, $\dot{w}$, for $0.1<\hat{c}_{i}<$ 1.0. $\left(s / w_{n}=11.5 ; \Lambda=1.1258595 ; \bar{U} / \Delta U=0.5 ; m_{2}=1.65 ; T_{2}=1\right)$. 


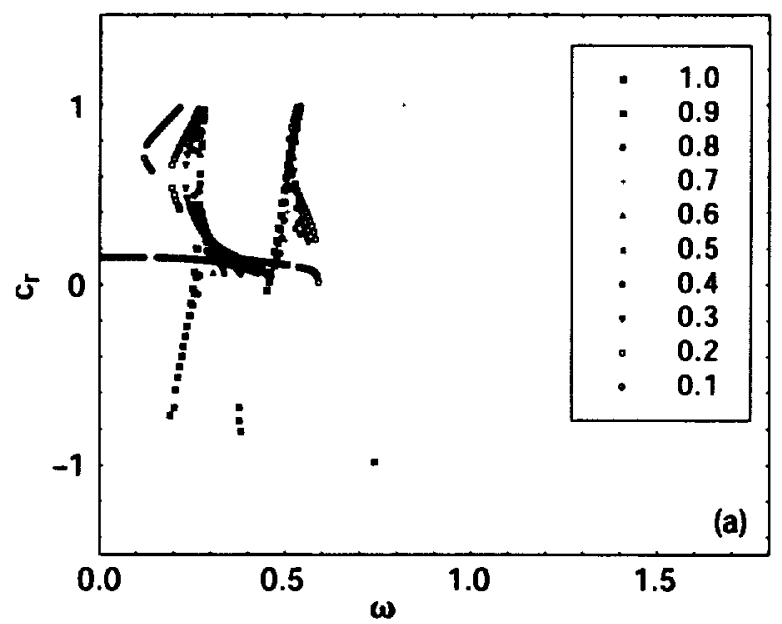

Figure 8.-(a) Phase velocity eigenvalue, $c_{r}$, verses frequency, $\dot{w}$, for 0.1 $<\dot{c}_{i}<1.0 .\left(s / w_{n}=11.5 ; \Lambda=1.111845 ; \dot{U} / \Delta U=0.5 ; m_{2}=1.75 ; T_{2}=1\right)$.

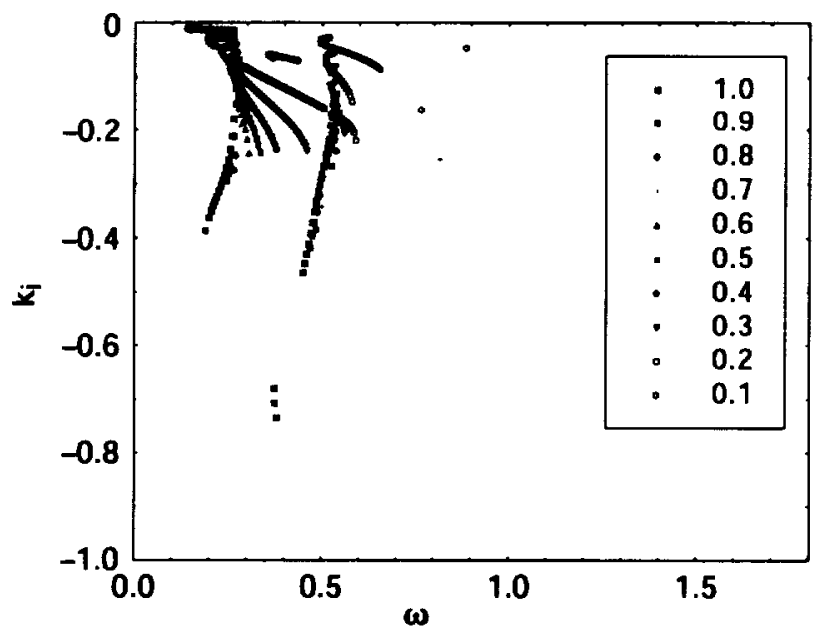

Figure 8.-(b) Amplification, $k_{i}$, verses frequency, $w_{\text {, for }} 0.1<\hat{c}_{i}<$ 1.0. $\left(s / w_{n}=11.5 ; \Lambda=1.111845 ; U / \Delta U=0.5 ; m_{2}=1.75 ; T_{2}=1\right)$.

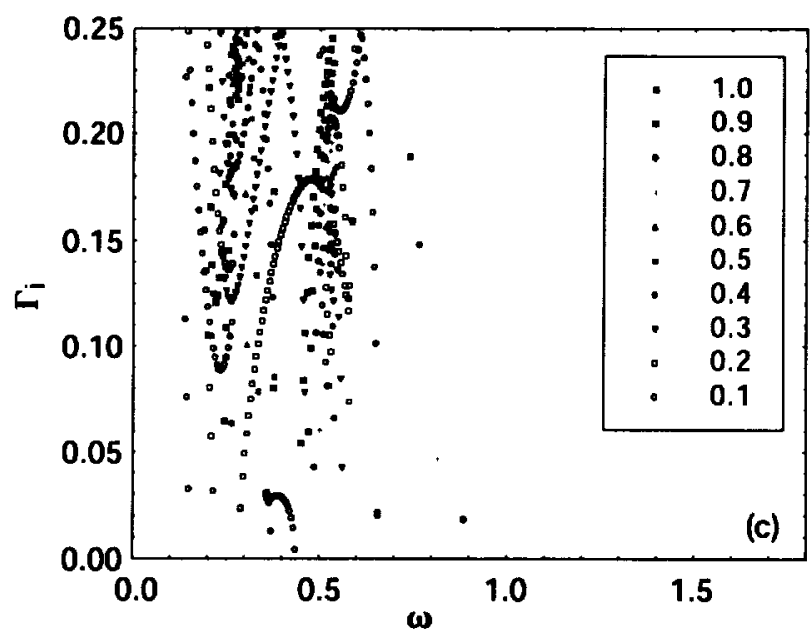

Figure 8.-(c) Periodicity factor, $\Gamma_{j}$, verses frequency, $\hat{w}$, for $0.1<\hat{c}_{i}<$ 1.0. $\left(s / W_{n}=13.7 ; \Lambda=1.111845 ; U / \Delta U=0.5 ; m_{2}=1.75 ; T_{2}=1\right)$. 


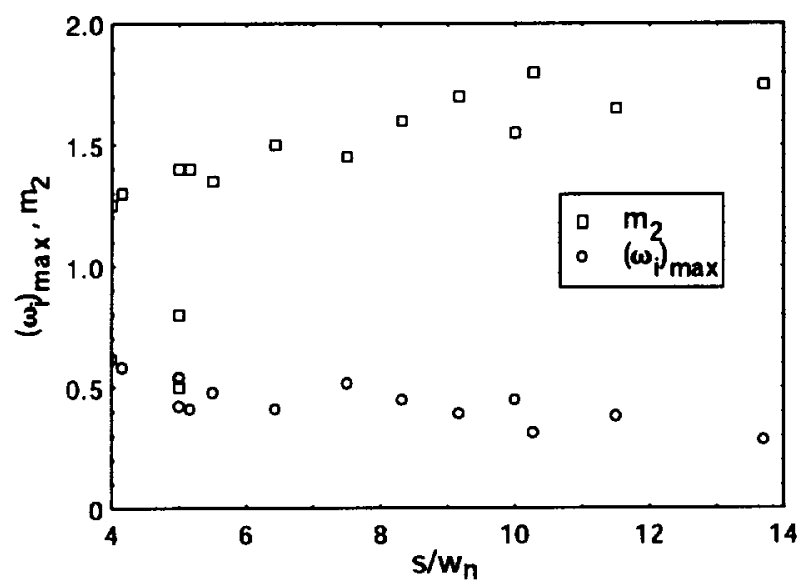

Figure 9.-Temporal growth rate, $\left(\tilde{\omega}_{i}\right)_{\max }$, results ${ }^{6}$ for a range of relative Mach numbers, $m_{2}$, and nozzle spacings, $s / w_{n}$.

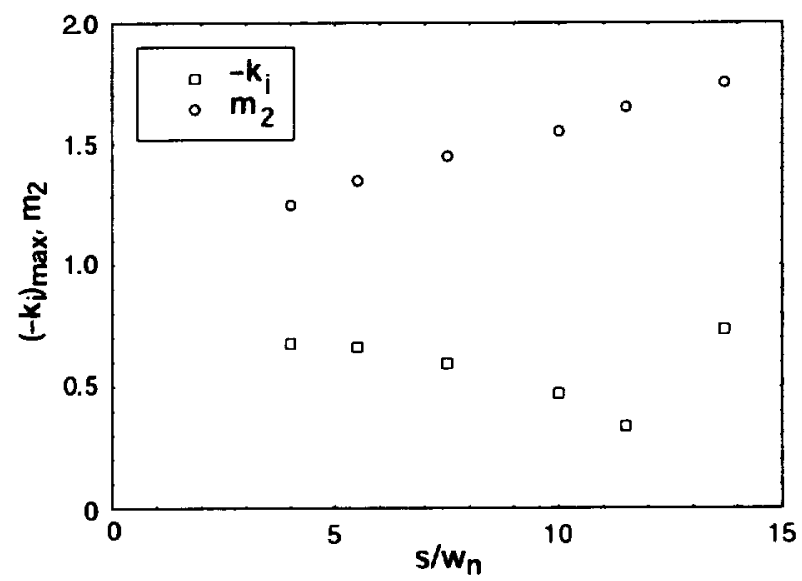

Figure 10.-Spacial growth rate, $\left(\dot{\omega}_{i}\right)_{\max }$, results for a range of relative Mach numbers, $m_{2}$, and nozzle spacings, $s / w_{n}$. 


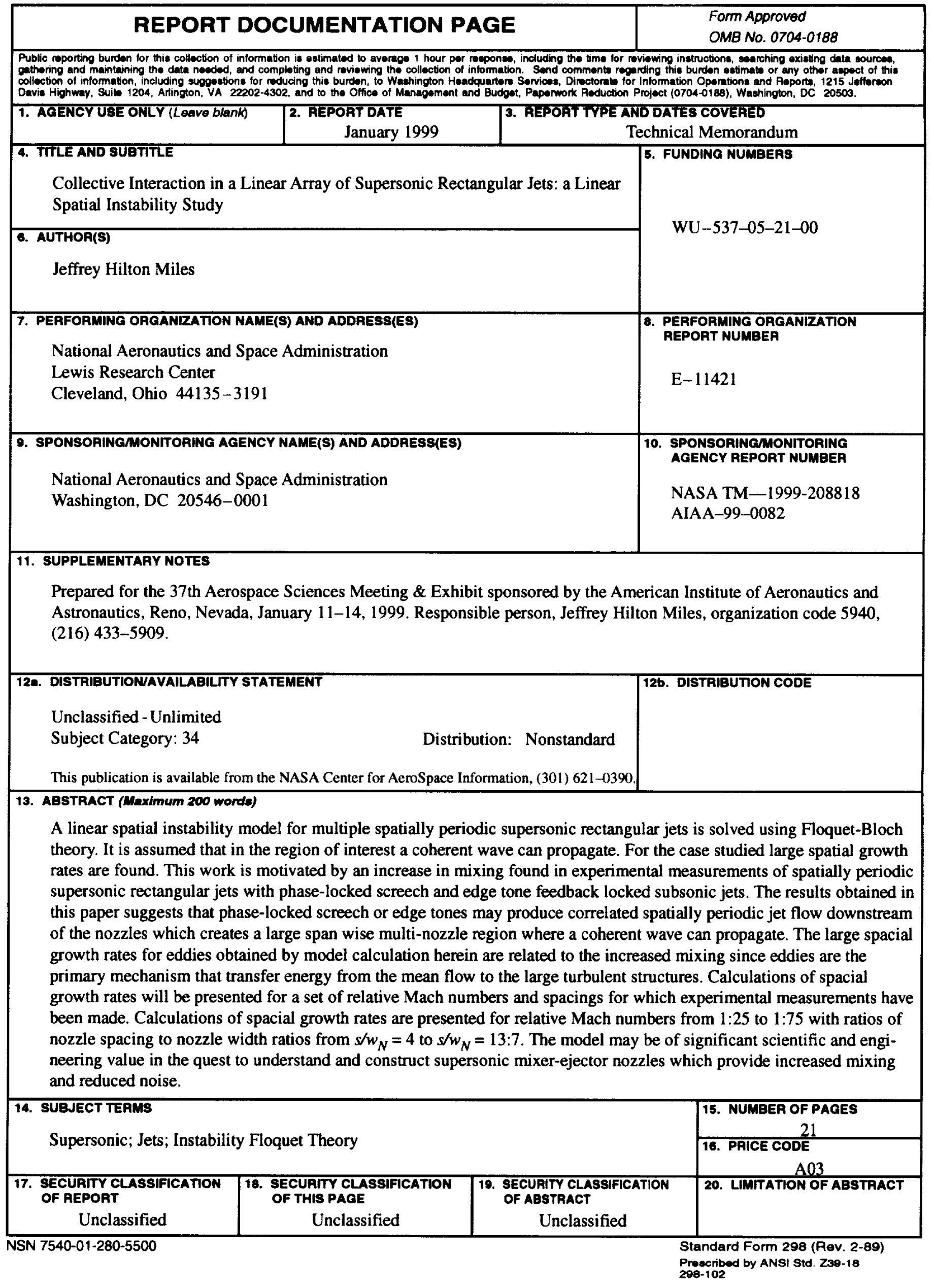

